\title{
Erratum to: Effect of atmosphere on the synthesis of potassium titanate
}

\author{
LI Jie $^{\mathrm{a}, \mathrm{b}, \mathrm{c}}$, WANG Yong ${ }^{\mathrm{b}, \mathrm{c}}$, WANG Lina ${ }^{\mathrm{b}, \mathrm{c}}$, SUN Tichang ${ }^{\mathrm{a}}$, QI Tao ${ }^{\mathrm{b}, \mathrm{c}}$, and ZHANG Yi ${ }^{\mathrm{b}, \mathrm{c}}$ \\ ${ }^{a}$ School of Civil and Environmental Engineering, University of Science and Technology Beijing, Beijing 100083, China \\ ${ }^{\mathrm{b}}$ National Engineering Laboratory for Hydrometallurgical Cleaner Production Technology, Institute of Process Engineering, Chinese Academy of Sciences, Beijing \\ 100190, China \\ ${ }^{\mathrm{c}}$ Key Laboratory of Green Process and Engineering, Institute of Process Engineering, Chinese Academy of Sciences, Beijing 100190, China \\ (C) The Nonferrous Metals Society of China and Springer-Verlag Berlin Heidelberg 2010
}

\section{Erratum to: RARE METALS}

Vol. 29, No. 3, Jun 2010, p. 280

DOI: $10.1007 / \mathbf{s} 12598-010-0049-8$

In the online version of the article the first name of the first author is misspelled. The correct spelling is "Jie".

The online version of the original article can be found at http://dx.doi.org/10.1007/s12598-010-0049-8 